\title{
Narrative review of theoretical considerations regarding HITHOC between past and future
}

\author{
Tamas F. Molnar ${ }^{1,2}$, Andras Drozgyik ${ }^{2}$ \\ ${ }^{1}$ Department of Operational Medicine, Faculty of Medicine, University of Pécs, Pécs, Hungary; ${ }^{2}$ Chair of Surgery, Faculty of Medicine, University of \\ Pécs/Dept Surgery, Aladar Petz University Teaching Hospital, Győr, Hungary \\ Contributions: (I) Conception and design: TF Molnar; (II) Administrative support: TF Molnar; (III) Provision of study materials or patients: TF \\ Molnar; (IV) Collection and assembly of data: All authors; (V) Data analysis and interpretation: TF Molnar; (VI) Manuscript writing: Both authors; \\ (VII) Final approval of manuscript: Both authors. \\ Correspondence to: Tamas F. Molnar. Department of Operational Medicine, Faculty of Medicine, University of Pécs, H7622 Pécs Szigeti u. 12, \\ Hungary. Email: tfmolnar@gmail.com.
}

\begin{abstract}
Hyppocrates constructed the medicines-surgery-energy triangle which includes all therapeutical modalities. Hyperthermic intraoperative chemotherapy (HITHOC) is a synergy-based single stage multimodality treatment encompassing the locoregional manifestation of the systemic malignant process. Pleural space, thermal effect, lavage/irrigation and chemotherapy represent the basic science ports of the network hub: HITHOC. The malignant transformation and process of the pleural surface (and underlying lung) challenges space management and tissue control. Thermotherapy without local chemotherapy is insufficient, similar to the normothermic local irrigation aligned with anticancer agents. The local administration of combined heat-transfer fluid and chemotherapy with or without subsequent surgical removal offers reasonable outcome in extensive primary pleural neoplasms (malignant mesothelioma), advanced (> Stage IIIA) NSCLC, functionally inoperable lung cancer and pleural carcinosis from extrathoracic malignancies. Measured by symptom-free survival and the quality of life, HITHOC in its present form, offers a modest yet fully substantiated solution. HITHOC in combination with the local application of targeted therapy and/or immunotherapy administered in the pleural space are currently under investigation. Additional development including new acting substances, their solvents and the means regarding surgical delivery and anesthesiology techniques are sign posts up ahead. Level 2 evidence are required in order to stepping up the recommendation levels, rewriting protocols and guidelines, in which HITHOC earns its revered position in the decision making process it deserves.
\end{abstract}

Keywords: Intrapleural hyperthermy; pleurodesis; video-assisted thoracoscopic surgery (VATS)

Submitted Aug 13, 2020. Accepted for publication Feb 26, 2021.

doi: $10.21037 /$ atm-20-5855

View this article at: http://dx.doi.org/10.21037/atm-20-5855

\section{Introduction}

Unearthing the philosophical roots of a therapeutical modality may seemingly be an outdated approach used to explore core issues during the search for a hidden path leading to the promised land of increased efficacy, better survival not to mention cost-benefit optimization. The Greek philosopher Empedocles (490-430 BC) laid down the concept of the four elements representing constituents of the World: earth, fire, water and air (1). This concept, further developed by Aristoteles inevitably found its way into the medical teachings of Asclepius and Hippocrates (2). Causes of diseases and treatment modalities were implemented into this quadrangular theorem in which temperature and fluid-content (humidity) served as the independent variables. Hippocrates while educating us, his very late disciples, while referencing to the complete horizon of medical interventions wrote: "Those diseases 
which medicines do not cure, iron cures; those which iron cannot cure, fire cures; and those which fire cannot cure, are to be reckoned wholly incurable." (3). Decoding the particular modalities one by one, from the hierarchy applicable to present day cancer treatment ushers in a unique transformation, one evolving into a tripod schematic. Medicine is to chemotherapy added by targeted and/or immunotherapy. Surgery is the direct descendant of the iron in the text of Hyppocrates, and refers to the scalpel. Fire as a per sé caloric treatment, originally in the form of heated oils or a blazing scarlet-red metal rod, yet astonishingly, present day hyperthermy matches and synchronizes to the expression. Radiotherapy also encapsulates the very same notion. Hyperthermic Intraoperative Chemotherapy (HITHOC) is an exquisite example regarding the modern transformation of the antiquated holistic concept turning all arms against the malignant processes. The scope of the present review is limited to intrapleural HITHOC (plHITHOC), excluding focused hyperthermy (tumor ablation). However, being voluntarily self-quarantined into the thoracic cage facilitates a closer focused look at the context of loosely related issues in their supportive role passim. Three basic science approaches leading to our main target: HITHOC of the pleural surface will be circumnavigated. Anatomical, physical and (bio)chemical aspects of hyperthermy are investigated in order to create a take-off platform for ideas leading to further developments.

Annotating a trajectory representing the future of the plHITHOC, is much like a task in putting jigsaw puzzle pieces together. The various pieces are positioned according to shape (strength) and potential (efficacy, toxicity) future union (interaction) with its partner(s). And so it is with the particular notions regarding pleural space, thermal effect, lavage/irrigation and chemotherapy, our primary actors.

We present the following article in accordance with the Narrative Review reporting checklist (http://dx.doi. org/10.21037/atm-20-5855).

\section{Anatomy: the pleural space and its walls}

The healthy pleural surface features the unique function in securing a frictionless movement between the parietal and visceral envelopes. A minimum amount of hypooncotic fluid is responsible for "oiling" the apparatus. Average intrapleural fluid turnover is estimated at or about 0.1$0.3(0.02-2.0) \mathrm{mL} / \mathrm{kg} / \mathrm{h}$. Visceral pleura produces majority of pleural fluid, while the reabsorption is accomplished by parietal pleural lymphatics. There is an apicobasal disribution among the production/absorption, in which the diaphragmatic mediastinal surfaces are responsible for the latter (4). The rate of flow seen in pleural lymphatics can lead to increases in response to an increase in pleural fluid filtration. The oncotic pressure is dependent on the macromolecular contents of the pleural fluid (5). Any potential mismatch between the production and absorption volume/capacity and/or change in the colloid/ capillary oncotic and hydrostatic pressures of the fluid will likely result in the accumulation of the intrapleural fluid and subsequent compression on the underlying lung parencyhma. Apposition and the mesothel reaction of the two opposing layers resulting in symphisis leads to the elimination of the virtual space. While such a reaction is a dreaded consequence of tissue trauma in the abdominal cavity leading to the adhesions causing mechanical ileus (6), pleurodesis (7) is a much desired phenomenon in thoracic medicina and surgery. Assisted pleural adhesions in form of chemical pleurodesis is a well established method in coping with malignant pleural effusions (MPF) (8). The telling lack of mentioning plHITHOC in the combined European MPF guideline (9) as a viable therapeutical option is clear proof, the modality is out of focus in spite of its evidence- based applications (10). The hope of achieving local antitumor activity while performing pleurodesis by chemotherapeutical agents remains to be as of yet unfulfilled (11), and the results presented thus far are unconvincing (12). One of the most striking features regarding the contour of the pleural envelope affected by pathologic processes and malignant deposits are their diffuse and wildly irregular shape. This bizarre geometry and the extension of the malignant process tipically excludes the "iron/blade" component of the hyppocratean triangle. Irrigation overcomes the disadvantages regarding the static "filling up the cavity" as the turbulent streams reach the outermost recesses. The idea of irrigating the space surrounded by tumorous infiltration originates from the local treatment of abscesses and stage II thoracic empyaema (13). The concept of inflammatory process control by diluted substances has been transplanted into the field of topical anticancer treatment. Historical substances intended for wound treatment with acidificating agents such as wine (14) are distant reminders how the oncotic/hydrostatic pressure and $\mathrm{pH}$ are interrelated (15) during plHITHOC. Systematic drug delivery targeting malignant cells on or below the pleural surface bears a theoretical alternative in direct contact by flooding the cave with fluid (16) with or without continuous irrigation. 
Medication in the classic hyppocratean meaning of the therapeutical modalitity implies systemic chemotherapy. Synchron or adjuvant irrigation of an empty thoracic space created by (pleuro)pneumonectomy for malignancy with normothermic chemoterapeutics emerged in the 1990s (17). Armed with the advent of targeted therapy and immunotherapy the pleural space was plausibly offered. While the concept of topical application of anti-VEGF and anti-EGFR (18) sounds reasonable, the method is still confined to the wetlabs. Experiences with locally administered immunotherapy agents are promising to a certain degree, yet are far from earning a consolidated position in clinical practice (19). The third option offered by Hyppocrates is fire, which can be translated either to hyperthermic therapy or radiotherapy.

\section{Physics: the heat}

There is a citation causing more harm than benefit to HITHOC circulating within the commonly referred to, alternative/complementary medicine domain, "give me the power to produce fever and I'll cure all disease" supposed words credited to Parmenides, the presocratean philospher (540?-460?BC). Giving medical credit to his cosmology whose fragments (20) are strewn over time is like stating there is a hidden recipe in the form of a mysterious panacea for all maladies. When more specific pathologies are in question, the picture is not so hazy. Systemic and sudden heating in the form of a provoked fever is a dated concept regarding the treatment of mental diseases (21). It was around 100 years ago in which Jauregg treated paralysis as a result of advanced syphilis with malaria reportedly achieving a response rate of $30 \%$ (22). Psychiatry is the territory of wide grey zones in which definitons are concerned, therefore outcomes hard to standardize. Malignant tumor responses to fevers alone are more objective, and the literature in this aspect is considerably transparent (23). Heat as a trigger of the immune system (24), a sort of biological therapy is a more recently evolving concept (25), however the cause-consequence question as of yet remains unanswered.

Opposed by focused heat directed at the solid tumor mass in any form of tumor ablation which is an established palliative method $(26,27)$ local fluid hyperthermy with no added substance via irrigation appears to be a suboptimal solution (28). Seemingly, the concept appeared plausible and the application simple, yet the results lacked conviction (29).

\section{Chemotherapeutics and other anticancer agents}

A lengthy debate regarding the potential survival benefit of intrapleurally administered and irrigated normothermic chemotherapeutics concluded in 1995 with negative results (30). Drugs and times changed, yet no fundamentally contradictionary observations followed $(31,32)$.

The magic bullet of the cisplatin of the 1990s (33) and subsequent other drugs including bleomicyn, etoposid and later the taxanes (34), all failed to achieve a measurable antitumor effect in the pleural space. Capillary leakage syndrome, toxic pulmonary injury, unpredictable absorption rate/depth were responsible for the unfavourable outcomes of the normotermic tests associated with these drugs $(35,36)$. Encouraging experiences with bladder irrigation and other compartmental administrations, including intrathecal therapies (37) missed the pleural space. The jury is still out regarding the question of the efficacy of antigen triggered antitumor immunological response (38). Recently, intrapleural immunotherapy ushers new indications (19). Monoclonal antibodies such as bevacizumab and similar actors, cope with the metastasizing tumor causing MPE offers a logical bifocal action (39). To make a complicated picture more confusing, there is an accumulating number of observations in reference to beneficial alterations regarding therapy resistance in both directions of immunotherapies and chemotherapies as seen in pulmonary malignancies. Since we are are focusing on the local application of these agents, the question is beyond our present interest.

\section{Crossroad}

Systemic cisplatin based chemotherapies and the taxanes radically improved median survivals from the mid-1990s, and many patients survived long enough to develop MPE, a treatment challenge. Vascular endothel growth factor (VEGF) promoting blood vessel permeablity was a iatrogenic cause in the drastic increase of MPE. Intrapleurally administered chemotherapies failed to fulfill the promise in keeping the process at bay. Paradigm changes in oncotherapies regarding extrathoracic malignancies, especially breast cancer (40), and large bowel malignancies (41) produced many long survivors and very late relapses and more importantly pleural metastases. Combined anticancer treatment results had to be interpreted in a matrix in which many shades of a grey zone replaced the former black and white division line between the categories of curative and palliative 
treatments. Mesothelioma thus far as a neglected emerging entity posed as the third element (42) The four main factors, and several others not independent from one another, all in the context of the pleural space and underlying lung were in need of an efficient therapeutical solution. One of the answers was HITHOC.

Dawning from the early 1990s an emerging number of cases were treated using hyperthermy and results have been published (43) covering the NSCLC (44), the mesothelioma (45) and the metastatic pleural malignancies domains reached the present state of art. Different plHITHOC methodologies are investigated, hyperthermic chemotherapy with or without surgery, synchron or adjuvant setting are presented, including a variation regarding delivery teactics (46-49).

Currently the distribution regarding the origin of the publications show the method is center-of-experience linked, scattered throughout Italy, Germany (50) and France with a seemingly similar pattern when compared with the early stage of the evolving technique of video-assisted thoracoscopic surgery (VATS) in Europe around the turn of the new milleneum. Dedicated centers in Turkey and USA collected vast experiences, while Chinese authors $(10,29)$ are accumulating and publishing encourageingly positive mass experiences and basic research.

Presently, the journal covers the state of art regarding HITHOC, and there is no need to discuss the recent evidences in their full depth nor to detail the existing controversies. What is the most pressing issue is, where to go from here? A notion pro futuro.

\section{The next steps}

Nanotechnology is one of the fields exalting promise in which a high definition delivery of the antitumor agents is the key element. Exploiting the interaction of the components is the modern equivalent of the hyppocratean category representing fire: hyperthermy and irradiation, the potentials of the heat radiosensitivation are perhaps worth exploring. Magnetic-nanoparticle-mediated intracellular hyperthermia aims at the localized tumor heating with minimal or no collateral damage (51). The temperature threshold is a tor about $43{ }^{\circ} \mathrm{C}$. Heat-shock protein expression causing tumor-specific immune response may be an added value. Another nanotechnical method is to optimize the chemotherapeutic agent delivery (52-54). Temperature dependence regarding the chemical reaction rate and diffusion coefficients is one of the basic rules,
HITHOC handsomely applies (55). Differences in heat sensitivity among particular cell types and tissues are paramount regarding selective effects and reactions. The same time-temperature relationship has been observed regarding heat inactivation in proteins, The combination of HITHOC with ipsilateral lung perfusion (56) used in cancer control is a theoretical option.

There are two more questions to discuss, more specifically surgical issues. The first topic is the oncotic pressure of the intracavitary fluid and the interdependence with the $\mathrm{pH}$. The standard medium for chemotherapeutics use implies plHITHOC is the isotonic solution. The pharmacokinetics of the drugs are optimized for their original intravenous application, in which vascular wall protection is a priority. However, the pleural surface is more resilient than the vascular endothel, therefore a more relaxed attitude is permitted. The pharmacodynamics of the given acting substance, not the solvent itself serves as the decisive factor. Intraoperative irrigation using isotonic salt in order to protect the serosal cell layers of intraabdominal organs is a generally established preventive maneuver. The release of a freed tumor cell by the intracavitary maneuvers in oncosurgery is a well documented phenomenon in the abdomen (57) and also the thorax (58). Turnbull's no-touch precept (59), once a universal cancer surgery command is not yet entirely cancelled. The intraabdominal/thoracic organ trauma during extensive video controlled procedures do not seem to confirm the validity regarding the 50 years old teaching, or at least the published results do not reflect it. Only a few publications are available referencing the clinical practice of using sterile water or hypooncotic (hypotonic) fluid in order to cause malignant cell cytolysis, or osmotic death. The hypotonic shock (60) kills the freed tumor cell by the osmotic imbalance when excess water is diffused into the cell through the cell membrane or through the aquaporins, the selective membrane channels. Reaching the membrane capacity, the malignant tumor cell bursts. Many of us, who have been following the same practice for ages did not consider this protocol worth of a publication. Chloride ion channel blockers have been proven to increase the efficacy of cellular hypotonic shock during pancreas surgery (61). Oncocytolytic maneuvers are reported during gastric (62), and colorectal (63) surgeries. Surprisingly, published papers are scarce regarding the thoracic cavity (64), a place where pleural surface $\mathrm{pH}$ protection is not a priority. Urologists, pioneers of intracavitary immunotherapy decades before the monoclonal antibodies became available, investigated the 
tumor cell killing capacity of sterile water (65). The acting mechanism theories regarding how water induces autocrine stimulation leading to cell death by apoptosis are indeed numerous (66). There is indirect evidence referencing the effect, in which there is increased oncotic pressure in solid tumors (67). The question emerging here, "Will the use of hypooncotic solvents for the intrapleurally administered anticancer drugs during plHITHOC increase therapeutical efficacy?"-begs for consideration.

Minimal access delivery of plHITHOC via VATS (68) is yet another field witnessing development, especially the issue of anesthesia. The application of experiences gained during noninvasive ventilation (NIV) regarding lung cancer surgery is promising territory (69). Anesthesia for HITHOC is a delicate subject for excessive systemic response to treatment (70). Recent modifications securing airways without positive end pressure bears the added value of beneficial pressure conditions on the lung parenchyma (71).

\section{Conclusions}

Extensive primary pleural neoplasms (malignant mesothelioma), advanced (> Stage IIIA) NSCLC, functionally inoperable lung cancer and pleural carcinosis due to extrathoracic malignancies (i.e., breast cancer and colonic cancer, etc.) are the main targets regarding the plHITHOC, a synergy-based single stage multimodality treatment. In the foreseeble future cancer medicine cannot cancel the methods of physically destroying the tumor mass, the locoregional manisfestation of a systemic disease (72). The combination of the systemic treatment and local control of a malignant pleural process are the key elements characteristc of plHITHOC, a chymera, and a hybrid approach for a disease which is symbolically best described as Cancer. One might argue that abundance of Greek philosophy surreptitiously infiltrated this review, but without understanding the basic principles of our art no Artificial Intelligence Wonder Algorythm can help us orientate throughout the labyrinth regarding pneumopleural malignancies.

Symptom free survival and quality of life are the two goals of oncosurgery. Measuring using these two parameters, plHITHOC in present form offers a modest yet well established solution. To become a standard procedure in the field plHITHOC must follow the pattern of emerging modalities regarding focused energy tumor ablation including high frequency and radiotherapy. The prospective studies presented thus far and cited here provide solid level III evidence is support regarding the efficacy of HITHOC treatment. Randomized studies are needed in stepping up the recommendation levels, rewriting protocols and guidelines, in which HITHOC is awarded its position in the decision making process it righteously deserves.

\section{Acknowledgments}

This paper, partly written during the 2020 SARS-COVID19 Pandemic Lockdown in quaranteen is dedicated to all those medical staff who paid their ultimate sacrifice in the fight to save the life of their patients.

Funding: None.

\section{Footnote}

Provenance and Peer Review: This article was commissioned by the Guest Editor (Marcello Migliore) for the series "Hyperthermic Intraoperative Chemotherapy (HITHOC) in thoracic surgical oncology" published in Annals of Translational Medicine. The article has undergone external peer review.

Reporting Checklist: The authors have completed the Narrative Review reporting checklist. Available at http:// dx.doi.org/10.21037/atm-20-5855

Conflicts of Interest: Both authors have completed the ICMJE uniform disclosure form (available at http://dx.doi. org/10.21037/atm-20-5855). The series "Hyperthermic Intraoperative Chemotherapy (HITHOC) in thoracic surgical oncology" was commissioned by the editorial office without any funding or sponsorship. The authors have no other conflicts of interest to declare.

Ethical Statement: The authors are accountable for all aspects of the work in ensuring that questions related to the accuracy or integrity of any part of the work are appropriately investigated and resolved.

Open Access Statement: This is an Open Access article distributed in accordance with the Creative Commons Attribution-NonCommercial-NoDerivs 4.0 International License (CC BY-NC-ND 4.0), which permits the noncommercial replication and distribution of the article with the strict proviso that no changes or edits are made and the original work is properly cited (including links to both the 
formal publication through the relevant DOI and the license). See: https://creativecommons.org/licenses/by-nc-nd/4.0/.

\section{References}

1. Kingsley P. Empedocles and His Interpreters: The FourElement Doxography. Phronesis 1994;39:235-54.

2. Savel RH, Munro CL. From Asclepius to Hippocrates: The Art and Science of Healing. Am J Crit Care 2014; 23:437-9.

3. Hyppocrates Aphorisms. Cited by: Haeger K. The illustrated history of surgery. London, UK: Harold Starke, 1988:40.

4. Miserocchi G Physiology and pathophysiology of pleural fluid turnover. Eur Respir J 1997;10:219-25.

5. Krishna R, Rudrappa M. Pleural Effusion. In: StatPearls. Treasure Island (FL): StatPearls Publishing; 2020 last accessed: 12.08.202. Available online: https://www.ncbi. nlm.nih.gov/books/NBK448189/

6. Tabibian N, Swehli E, Boyd A et al. Abdominal adhesions: A practical review of an often overlooked entity. Ann Med Surg (Lond) 2017;15:9-13.

7. Rodriguez-Panadero F, Montes-Worboys A. Mechanisms of pleurodesis. Respiration 2012;83:91-8.

8. Dixit R, Agarwal KC, Gokhroo A, et al. Diagnosis and management options in malignant pleural effusions. Lung India 2017;34:160-6.

9. Bibby AC, Dorn P, Psallidas I, et al. ERS/EACTS statement on the management of malignant pleural effusions Eur Respir J 2018;52:1800349.

10. Zhou H, Wu W, Tang X, et al. Effect of hyperthermic intrathoracic chemotherapy (HITHOC) on the malignant pleural effusion: A systematic review and meta-analysis. Medicine (Baltimore) 2017;96:e5532.

11. Mierzejewski M, Korczynski P, Krenke R, et al. Chemical pleurodesis - a review of mechanisms involved in pleural space obliteration. Respir Res 2019;20:247.

12. Hsu LH, Feng AC, Soong TC, et al. Clinical outcomes of chemical pleurodesis using a minocycline. Ther Adv Respir Dis 2019;13:1753466619841231.

13. Molnar TF. Current surgical treatment of thoracic empyema in adults. Eur J Cardiothorac Surg 2007;32:422-30.

14. Manring MM Hawk A, Calhoun JH, Treatment of War Wounds: A Historical Review. Clin Orthop Relat Res 2009;467:2168-91.

15. Will BR, Brace RA. Physiological effects of $\mathrm{pH}$ changes on colloid osmotic pressures. Am J Physiol 1985;248:H890-3.
16. Lerza R, Esposito M, Vannozzi M, et al. High dose of intrapleural cisplatin in a case of malignant pleural mesothelioma. Cancer 1994;73:79-84.

17. Rusch VW, Niedzwiecki D, Tao Y, et al. Intrapleural cisplatin and mitomycin for malignant mesothelioma following pneumonectomy: pharmacokinetic studies. J Clin Oncol 1992;10:1001-6.

18. Acencio MMP, Puka J, Alvarenga VA, et al. Intrapleural targeted therapies (anti-VEGF and anti-EGFR) in the model of malignant pleural effusion. Oncotarget 2017;8:105093-102.

19. Murthy V, Katzman D, Sterman DH. Intrapleural immunotherapy: An update on emerging treatment strategies for pleural malignancy. Clin Respir J 2019;13:272-9.

20. Coxon AH. The Fragments of Parmenides: A critical text with introduction, translation, the ancient testimonia and a commentary. Las Vegas/Zurich/Athens: Parmenides Publishing, 2009.

21. Kragh JV. Malaria fever therapy for general paralysis of the insane in Denmark. Hist Psychiatry 2010;21:471-86.

22. Whitrow M. Wagner-Jauregg and fever therapy. Med Hist 1990;34:294-310.

23. Carlson RD, Flickinger JC, Snook AE. Talkin' Toxins: From Coley's to Modern Cancer. Immunotherapy Toxins (Basel) 2020;12:241.

24. Krone B, Kölmel KF, Grange JM. The biography of the immune system and the control of cancer: from St Peregrine to contemporary vaccination strategies. BMC Cancer 2014;14:595.

25. DeNardo GL DeNardo SJ. Update: Turning the Heat on Cancer. Cancer Biother. Radiopharm 2008;23:671-80.

26. Brace C. Thermal tumor ablation in clinical use. IEEE Pulse 2011;2:28-38.

27. Haen SP, Pereira PL, Salih HR, et al. More Than Just Tumor Destruction: Immunomodulation by Thermal Ablation of Cancer. Clin Dev Immunol 2011;2011:160250.

28. Moon Y, Kim KS, Park JK. Simple intrapleural hyperthermia at thoracoscopic exploration to treat malignant pleural effusion. J Cardiothorac Surg 2015;10:136.

29. Kang MQ, Zhou L, Chen ZZ, et al. Intrapleural thermotherapy for malignant pleural effusion casued by lung carcinoma. Lung Cancer 2000;29:S1.105.

30. Figlin R, Mendoza E, Piantadosi S. Intrapleural Chemotherapy without pleurodesis for malignant pleural effusions Chest LCSG Trial 861. Chest 1994;106:363S-6S.

31. Yoshida K, Sugiura T Takifuji N, et al. Randomized phase 
II trial of three intrapleural therapy regimens for the management of malignant pleural effusion in previously untreated non-small cell lung cancer: JCOG 9515. Lung Cancer 2007;58:362-8.

32. Murthy V, Mangalick K, Sterman DH. Intracavitary Therapeutics for Pleural Malignancies. Clin Chest Med 2018;39:195-209.

33. Horita N, Nagashima A, Nakashima K, et al. The best platinum regimens for chemo-naive incurable nonsmall cell lung cancer: network meta-analysis. Sci Rep 2017;7:13185.

34. Yared JA, Tkaczuk KHR. Update on taxane development: new analogs and new formulations Drug Des Devel Ther 2012;6:371-84.

35. Zhong LZ, Xu HY, Zhao ZM, et al. Comparison of efficacy and toxicity between nedaplatin and cisplatin in treating malignant pleural effusion. Onco Targets Ther 2018;11:5509-12.

36. Lombardi G, Nicoletto MO, Gusella M. Intrapleural paclitaxel for malignant pleural effusion from ovarian and breast cancer: a phase II study with pharmacokinetic analysis. Cancer Chemother Pharmacol 2012;69:781-7.

37. Byrnes DM, Vargas F, Dermarkarian C, et al. Complications of Intrathecal Chemotherapy in Adults: Single-Institution Experience in 109 Consecutive Patients. J Oncol 2019;2019:4047617.

38. Bibby AC, Walker S, Maskell NA. Are intra-pleural bacterial products associated with longer survival in adults with malignant pleural effusions? A systematic review. Lung Cancer 2018;122:249-56.

39. Zongwen S, Song K, Cong Z, et al. Evaluation of efficacy and safety for bevacizumab in treating malignant pleural effusions caused by lung cancer through intrapleural injection. Oncotarget 2017;8:113318-30.

40. Ades F, Tryfonidis K, Zardavas D. The past and future of breast cancer treatment-from the papyrus to individualised treatment approaches. Ecancermedicalscience 2017;11:746.

41. Damin DC, Lazzaron AR. Evolving treatment strategies for colorectal cancer: A critical review of current therapeutic options. World J Gastroenterol 2014;20:877-87.

42. Smith DD. The History of Mesothelioma. In: Pass HI, Vogelzang NJ, Carbone M. (eds). Malignant Mesothelioma. New York, NY: Springer, 2005.

43. Monneuse O, Beaujard A, Guibert B, et al. Long-term results of intrathoracic chemohyperthermia (ITCH) for the treatment of pleural malignancies. Br J Cancer
2003;88:1839-43.

44. Kimura M, Tojo T, Naito H, et al. Effects of a simple intraoperative intrathoracic hyperthermotherapy for lung cancer with malignant pleural effusion or dissemination. Interact Cardiovasc Thorac Surg 2010;10:568-71.

45. Zhao ZY, Zhao SS, Ren M, et al. Effect of hyperthermic intrathoracic chemotherapy on the malignant pleural mesothelioma: a systematic review and meta-analysis. Oncotarget 2017;8:100640-7.

46. Migliore M, Nardini M. Does cytoreduction surgery and hyperthermic intrathoracic chemotherapy prolong survival in patients with N0-N1 nonsmall cell lung cancer and malignant pleural effusion? Eur Resp Rev 1953 2019;28:190018.

47. Yi E, Kim D, Cho S, et al. Clinical outcomes of cytoreductive surgery combined with intrapleural perfusion of hyperthermic chemotherapy in advanced lung adenocarcinoma with pleural dissemination. J Thorac Dis 2016;8:1550-60.

48. Ambrogi MC, Bertoglio P, Aprile V, et al. Diaphragm and lung preserving surgery with Hyperthermic Chemotherapy for Malignant Pleural Mesothelioma: a 10 year experience. J Thorac Cardiovasc Surg 2018;155:1857-66.e2.

49. Migliore M. Debulking surgery and hyperthermic intrathoracic chemotherapy (HITHOC) for lung cancer. Chin J Cancer Res 2017;29:533-4.

50. Ried M, Hofmann HS, Dienemann H, et al. Implementation of hyperthermic intrathoracic chemotherapy in Germany. Zentralbl Chir 2018;143:301-6.

51. Kobayashi T. Cancer hyperthermia using magnetic nanoparticles. Biotechnol J 2011;6:1342-7.

52. Christodoulou E, Nerantzaki M, Nanaki S, et al. Paclitaxel Magnetic Core-Shell Nanoparticles Based on Poly(lactic acid) Semitelechelic Novel Block Copolymers for Combined Hyperthermia and Chemotherapy Treatment of Cancer. Pharmaceutics 2019;11:213.

53. Contreras-Cáceres R, Cabeza L, Perazzoli G, et al. Electrospun Nanofibers: Recent Applications in Drug Delivery and Cancer Therapy. Nanomaterials (Basel) 2019;9:656.

54. Ito A, Honda H, Kobayashi T. Cancer immunotherapy based on intracellular hyperthermia using magnetite nanoparticles: a novel concept of "heat-controlled necrosis" with heat shock protein expression. Cancer Immunol Immunother 2006;55:320-8.

55. Dewey WC. Arrhenius relationships from the molecule and cell to the clinic. Int J Hyperthermia 2009;25:3-20. 
56. Van Schil PE, Hendriks JM, van Putte BP, et al. Isolated lung perfusion and related techniques for the treatment of pulmonary metastases. Eur J Cardiothorac Surg 2008;33:487-96.

57. Yonemura Y, Canbay E, Endou Y, et al. The natural history of free cancer cells in the peritoneal cavity. Expert Opin Pharmacother 2014;15:623-36.

58. Toufektzian L, Sepsas E, Drossos V, et al. Pleural lavage cytology: Where do we stand? Lung Cancer 2014;83:14-22.

59. Turnbull RB, Kyle K, Watson FR, et al. Cancer of the colon: the influence of the no-touch isolation technic on survival rates. Ann Surg 1967;166:420-7.

60. Shiozaki A, Ichikawa D, Kosuga T, et al. Regulation of osmolality for cancer treatment. J Physiol Sci 2017;67:353-60.

61. Nako Y, Shiozaki A, Ichikawa D, et al. Enhancement of the cytocidal effects of hypotonic solution using a chloride channel blocker in pancreatic cancer cells. Pancreatology 2012;12:440-8.

62. Iitaka D, Shiozaki A, Ichikawa D, et al. Blockade of chloride ion transport enhances the cytocidal effect of hypotonic solution in gastric cancer cells. J Surg Res 2012;176:524-34.

63. Takemoto K, Shiozaki A, Ichikawa D, et al. Evaluation of the efficacy of peritoneal lavage with distilled water in colorectal cancer surgery: in vitro and in vivo study. $\mathrm{J}$ Gastroenterol 2015;50:287-97.

64. Kosuga T, Shiozaki A, Ichikawa D, et al. Pleural lavage with distilled water during surgery for esophageal

Cite this article as: Molnar TF, Drozgyik A. Narrative review of theoretical considerations regarding HITHOC between past and future. Ann Transl Med 2021;9(11):954. doi: 10.21037/atm20-5855 squamous cell carcinoma. Oncol Rep 2011;26:577-86.

65. Taoka R, Williams SB, Ho PL, et al. In-vitro cytocidal effect of water on bladder cancer cells: The potential role for intraperitoneal lavage during radical cystectomy. Can Urol Assoc J 2015;9:E109-13.

66. Selzner N, Selzner M, Graf R, et al. Water induces autocrine stimulation of tumor cell killing through ATP release and P2 receptor binding. Cell Death Differ 2004;11:S172-80.

67. Stohrer M, Boucher Y, Stangassinger M, et al. Oncotic Pressure in Solid Tumors Is Elevated. Cancer Res 2000;60:4251-5.

68. Hu R, Jiang H, Li H, et al. Intrapleural perfusion thermo-chemotherapy for pleural effusion caused by lung carcinoma under VATS. J Thorac Dis 2017;9:1317-21.

69. Furák J, Szabó Z, Tánczos T, et al. Conversion method to manage surgical difficulties in non-intubated uniportal video-assisted thoracic surgery for major lung resection: simple thoracotomy without intubation. J Thorac Dis 2020;12:2061-9.

70. Kerscher C, Ried M, Hofmann HS, et al. Anaesthetic management of cytoreductive surgery followed by hyperthermic intrathoracic chemotherapy perfusion. J Cardiothorac Surg 2014, 9:125.

71. Furák J, Szabó Z. Spontaneous ventilation combined with double-lumen tube intubation in thoracic surgery. Gen Thorac Cardiovasc Surg 2021;69:976-82.

72. Molnar TF. Lung Cancer and Tuberculosis: Parallel Lives. J Thor Oncol 2019;14:S10-1. 